\title{
Challenges and Countermeasures of Chinese Cross-Border E-commerce Development in the United States
}

\author{
Sizheng Qu \\ Faculty of Finance and Law, Fu Jen Catholic University, New Taipei, Taiwan, 242 \\ *Corresponding author. Email: ShiLiShuang@cas-harbour.org
}

\begin{abstract}
With the upgrading of residents' consumption level and the popularization of overseas e-commerce platforms, the development of Chinese cross-border e-commerce has new opportunities. However, under the influence of the China-US trade frictions, Chinese cross-border e-commerce development in the United States has also encountered many difficulties and challenges.This article lists the difficulties and challenges that Chinese cross-border e-commerce encounter in their development in the US and proposes countermeasures to each of them.
\end{abstract}

Keywords: Cross-border E-commerce, China-US Trade Relations, Export Trade, Intellectual Property, Countermeasures

\section{INTRODUCTION}

Cross-border e-commerce could be viewed as an international business activity, which can trade and complete payment through e-commerce platforms, deliver goods and complete transactions through cross-border logistics [1]. At present, affected by the trade frictions between the US and China, Chinese cross-border e-commerce has encountered many difficulties and challenges, which are listed in this article, and corresponding countermeasures are given in each situation.

\section{CHALLENGES FACED BY CHINESE CROSS-BORDER E-COMMERCE DEVELOPING IN THE UNITED STATES}

\subsection{Irregular trading practices}

The export transaction model of cross-border e-commerce is different from that of traditional foreign trade. Its method of exporting goods can be briefly summarized as follows: Domestic sellers publish products' information on cross-border e-commerce platforms, and foreign buyers select products by browsing these platforms and then place an order on platforms to confirm the purchase of goods. After the foreign buyers pay the goods through the third-party payment platforms, the cross-border e-commerce platforms will notify domestic sellers to ship the goods. Domestic sellers will not get payment from the third-party payment platforms until foreign buyers receive the goods and confirm the receipts.

This transaction model has so many processes that it is pretty time-consuming for some e-commerce companies with large transaction volume, and it even may cause insufficient funds.Taking one of the third-party payment platforms --Paypal work as an example. The payment institution settles money every 10 days and remits the buyers' payment to the sellers' Paypal accounts. Sellers then transfer the money from the Paypal accounts to their domestic accounts. However, if the overseas customers have any questions about the purchased goods, the payment will be delayed by about 2 months to be received by sellers' accounts. In addition, the amount of funds remitted by Paypal to the seller is the aggregated amount during this period, not the transactions' details. Domestic sellers need to restore the aggregated amount to detailed numbers before submitting them to the bank for review [2].Therefore, some sellers and buyers will choose to use offline transactions instead of trading through third-party payment platforms. It means that sellers and buyers use traditional trading methods to complete transactions. After choosing the goods the foreign buyers want to buy on the cross-border e-commerce 
platforms, they will get in touch with the domestic sellers, and then privately reach agreements about their transactions' methods through email or other methods. This way can reduce the handling fees for sellers and the amount paid by buyers, which benefits both buyers and sellers. It not only allows domestic sellers to avoid hard transaction procedures, but also decreases the service fees that should be paid to third-party trading platforms as preferential prices for the goods sold. However, once this payment method is adopted, it is extremely prone to cause trade payment disputes. For foreign buyers, if there are problems in the quality, the timeliness of logistics or other aspects of the purchased goods, the buyers will have great difficulties in protecting their rights. It is also very easy to produce suspicion of illegal capital flows, and then cause a large number of third-party cross-border payment accounts of Chinese cross-border e-commerce companies in the United States to be frozen or even be cleared to zero, leading to huge economic losses.

\subsection{The reduction of the price advantage of export commodities}

Since China accessed to the WTO in 2001 and until 2017, Chinese trade surplus with the United States has continued to expand, showing an upward trend, which means that the trade imbalance between China and the United States has become more and more serious [3]. Therefore, since 2017, the United States has initiated trade frictions against China for the reason of its huge trade deficit with China. The intensive trade frictions between the two countries have had a huge impact on Chinese export cross-border e-commerce in many aspects, such as increased tariffs, reduced customs clearance efficiency, and higher logistics transportation prices. These inevitably lead to increase the costs of commodity transaction. Most of Chinese cross-border e-commerce exports mainly depend on 3C electronic products, clothing accessories, and agricultural products. These low-end products do not have core competitiveness, so they generally survive in the market with low prices. The increase in commodity transaction costs brought by the China-US trade friction has greatly weakened the price advantage of these commodities, which are known as 'Made in China'.

\subsection{Intellectual property rights disputes}

In the China-US trade frictions, the issue of intellectual property rights is also one of the key points of the disputes. From 2014 to 2019, the U.S. federal district courts accepted thousands of well-known brands' lawsuits against cross-border e-commerce trademark infringement in various countries. Among them, China was a key area, and there were at least 97 brands involved. In an anti-counterfeiting lawsuit against a certain brand, there were 1,549 defendants in
China (calculated based on websites and e-commerce platform accounts), and the court sentenced 200 million US dollars in damages in absence. In the Temporary Restraining Order before the absence judgment, 12,800 domain names were frozen [4]. What is behind this phenomenon? On the one hand, Chinese cross-border e-commerce is a new trade model, which has few experience to learn from, and Chinese laws and regulations on cross-border e-commerce intellectual property rights are not sound enough. Therefore, the problem of imbalance between policies and demands often arises. On the other hand, compared with China, the United States has a better legal system in terms of intellectual property protection. What's more, in almost thirty years, in order to fully satisfy and fulfill nation and it is local companies' interests, the United States has taken a lot of measures to protect intellectual property rights, such as revising traditional laws relevant to intellectual property and expanding protection scope of intellectual property rights [3]. Among them, 'Section 337' of the US Tariff Act specifically provided strong protection for the rights and interests enjoyed by its domestic intellectual property owners in import trade. This shows that there is still a big gap between China and the United States in the protection of intellectual property rights.

\section{COUNTERMEASURES FOR THE DEVELOPMENT OF CHINESE CROSS-BORDER E-COMMERCE IN THE UNITED STATES}

\subsection{Strengthening cooperation and government supervision among multiple departments}

Cross-border third-party payment platforms should understand changes in customer needs, and provide one-stop services with other departments in the face of customers with large transaction volumes. For example, a cross-border third-party payment platform can reach an agreement with the tax bureau in adding tax number registration, tax declaration and tax payment functions to reduce the costs of cash withdrawal and remittance for cross-border e-commerce [5]. In addition, it can also connect with the customs and logistics companies of China and the United States to achieve the rapid connection of transaction orders, logistics transportation and customs clearance, which can improve the efficiency of commodity transportation.

Chinese government should refine the laws and regulations on market access, anti-money laundering supervision, protection of customer rights and interests, and strengthen the verification of the transactions authenticity.

Chinese government should supervise cross-border payments with large transaction volumes and long 
capital chains independently by means of financial technology.

Chinese relevant departments should strengthen the cooperation and supervision with the US relevant departments, so that a special department for cross-border third-party payment supervision can be formed for China-US cross-border e-commerce to achieve the aim of information exchange and sharing.

\subsection{Expanding the market and establishing its own brand}

The main export destinations of Chinese e-commerce companies are developed countries, such as Europe and the United States. The main reason is that people in these countries have higher living standards and relatively mature online shopping systems. However, the Japanese and South Korean markets have also developed rapidly in recent years. At the same time, as the Internet continues to spread in other emerging market countries, their consumers have gradually formed cross-border shopping habits. In addition, with the spread and promotion of Chinese 'The Belt and Road Initiative' policy, China can exploit new consumer markets in countries along the routes.

According to statistics, in 2017, the total import and export volume between China and the countries along the 'The Belt and Road Initiative' reached 144.32 billion US dollars, accounting for $36.2 \%$ of China's total imports and exports, and the imports from 'The Belt and Road Initiative' countries totaled 666.05 billion US dollars, accounting for $39.0 \%$ of China's total imports [6]. In 2018, 9 countries including China and Russia established a new e-commerce cooperation mechanism to help enterprises relevant countries use e-commerce to open up international markets. The growth rate of cross-border e-commerce transactions between China and Cambodia, Kuwait, UAE, Austria and other countries all exceeded $100 \%$ compared with last year [6]. Therefore, China can use Japan, South Korea and other emerging market countries as a new development platform for China's cross-border e-commerce. Therefore, Chinese cross-border e-commerce can meet the needs of consumers in mature markets in Europe and the United States, while transferring the focus of the market to emerging markets and stepping up efforts to expand emerging markets.

Although the goods trade deficit between China and the United States is very large, the United States has maintained a long-term trade surplus in service trade.At the same time, the United States is a world leader in high-tech industries. Therefore, China should pay more attention to the development of science and technology, and the Chinese government should establish a sound policy system to support the product innovation of cross-border e-commerce and the establishment of new independent brands. China can achieve the aim of industrial transformation to reduce the dependence on the US market in technology and service by improving the level of independent research and development of technology products, creating more independent brands in the fields of service and technology.

\subsection{Refining and improving policies and systems}

The Chinese government should refine and improve policies and systems related to intellectual property rights and Chinese cross-border e-commerce companies should pay more attention to intellectual property rights and strengthen brand awareness.

In 2018, the E-commerce Law of the People's Republic of China goes into effect in China, which serves as the legal basis for cross-border e-commerce platforms in China to conduct economic and trade activities. In addition, on January 15, 2020, In order to facilitate trades between two countries, China and the United States have reached an agreement and signed the trade protection regulation, which protects intellectual property rights in e-commerce. However, due to the different legal backgrounds of the two countries, there are many differences on the aspect of rights and obligations in cross-border e-commerce between these two law versions. Besides, the regulation signed by two countries only restricted piracy and counterfeiting on e-commerce platforms in Chapter 1, Section 5, and did not specify other aspects of cross-border e-commerce intellectual property rights.On the whole, the treatment stipulated in this agreement is better than the treatment of intellectual property protection generally applicable in the field of Chinese e-commerce. The space between this agreement and Chinese relevant laws and regulations reveals that the intellectual property protection requirements of Chinese e-commerce entities should be increased as a direction of the intellectual property protection system of Chines e-commerce platforms [7]. Since Chinese cross-border e-commerce develops in the United States are subject to U.S. legal provisions, it is necessary to converge as much as possible with international trade conventions in legislation, law enforcement and dispute resolution.Additionally, in order to better protect the rights and interests of cross-border e-commerce companies and cross-border consumers in transactions, Chinese government should refine and improve the terms and conditions of the 'E-Commerce Law' by learning experiences from cross-border e-commerce practices and American intellectual property protection .

Chinese cross-border e-commerce companies do not have comprehensive understandings of the relevant aspects of the United States legal system, and they cannot realize the distinction between the scope of intellectual property protection between China and the 
United States. Therefore, many Chinese e-commerce operators faced investigations and prosecutions due to intellectual property disputes. However, because of the high judicial costs in the United States, after being sued, most merchants chose not to response to suits. What followed was that their third-party payment accounts would be frozen and the funds might even be cleared to zero, which casude serious economic losses to these companies. In order to change this situation, Chinese cross-border e-commerce companies should increase their awareness of intellectual property protection, such as being familiar with the trademarks and products of other brands.At the same time, they should understand the laws and regulations related to the scope of intellectual property protection in the United States actively. For example, when these companies design and produce products, they should avoid produce products which are too similar to other brands to prevent infringement of the intellectual property rights of other companies. For cross-border e-commerce platforms, if it is found that there are products sold on their platforms that have the risks of infringing intellectual property rights, the sellers should be contacted in time and the goods should be removed from the platforms, so that they can control the scope of infringement of intellectual property rights in time. Besides, if a Chinese cross-border e-commerce company has received a letter from a lawyer in the United States, which is related to intellectual property, the Chinese company should seek help from professionals immediately and respond to the lawsuit actively prevent its account of the third-party payment platform from being frozen and the funds to be cleared to zero.It is the best way for Chinese company to minimize the economic losses.

\subsection{Reasonable use of WTO trade dispute settlement mechanism}

According to the negotiation procedures of the WTO Trade Dispute Settlement Mechanism, Chinese cross-border e-commerce companies can apply to DSB (Dispute Settlement Body) and relevant councils and committees for consultation, and the American companies or individuals should respond within the limited time. If the negotiations between these two parties fail, Chinese cross-border e-commerce companies can invite expert groups to resolve trade disputes. Therefore, if Chinese cross-border e-commerce companies encounter US trade protection measures, they can use the WTO trade dispute settlement mechanism to protect their rights and interests.

\section{CONCLUSION}

In summary, in the era of economic globalization and rapid technological development, the cross-border e-commerce industry has developed rapidly. However, opportunities and challenges coexist, so appropriate response measures must be made in time to ensure the smooth development of Chinese cross-border e-commerce.

\section{REFERENCES}

[1] Ruoyun Huang. Cross-border e-commerce development status, risks and countermeasures[J].Northern Finance, 2021, (05):53-57

[2] Xiaoyan Yu, Liping Zhu. New development and new problems of Chinese cross-border e-commerce export under the new situation-Reflections based on WTO multilateral trade rules[J] .Foreign Economic and Trade Practices, 2017, (06):41-44

[3] Hui Chen. Research on the Countermeasures of Chinese Cross-border E-commerce Development to the U.S.[J] .Foreign Trade, 2020, (08):49-51+139

[4] Jiming Yi. Responses to the intellectual property risks of cross-border e-commerce: Taking the cases of Chinese e-commerce being sued in the United States[J].Intellectual Property Rights, 2021, (01):36-53

[5] Xinyu Jing. Research on the status quo and problems of third-party cross-border payment in China $[\mathrm{J}]$.Rural Economy and Technology, 2020, 31(14):91-93

[6] The Belt and Road Initiative Big Data Report on Trade Cooperation 2018[R]

[7] Ming Xu, Liang $\mathrm{Xu}$. Research on the optimization path of e-commerce intellectual property protection under the background of Economic and Trade Agreement between the Government of the People's Republic of China and the Government of the United States of America[J].International Trade, 2020, (03):37-43. 